\title{
22
}

\section{INSTRUCTION BASED ON COMPUTER SIMULATIONS}

\author{
Ton de Jong
}

\section{INTRODUCTION}

In the scientific debate on what is the best approach to teaching and learning, a recurring question concerns who should lead the learning process, the teacher or the learner (see e.g., Tobias \& Duffy, 2009)? Positions taken vary from a preference for direct, expository, teacher-led instruction (Kirschner, Sweller, \& Clark, 2006) to fully open studentcentered approaches that can be called pure discovery methods (e.g., Papert, 1980), with intermediate positions represented by more or less guided discovery methods (e.g., Mayer, 2004). This discussion also is a recurring theme in this chapter.

In discussing the issue of the role of guidance in instruction, the specific technology of computer simulations occupies a central place. Computer simulations, through their interactive character, offer a special opportunity for student-centered learning, while at the same time offering options for program or teacher led support and guidance of the learning process. Thus, a major goal of this chapter is to examine whether people learn better when simulations include substantial amounts of scaffolding that guides the learner (i.e., guided discovery method) or when simulations allow people to learn freely without much guidance (i.e., pure discovery method). Another goal of this chapter is to examine whether people learn better with computer simulations than with conventional instructional media.

Computer simulations are computer programs that have as their core a computational model of a system or a process. The system or process that is modeled normally has a natural world origin and the model that is created is usually a simplification (i.e., reduction and abstraction) of the real-world phenomenon (de Jong \& van Joolingen, 2007). Simplification is used because: (1) it is hard if not impossible to fully model the real world; (2) a simplification often suffices for the goal for which the model is built and greater realism also has costs in time and effort; and (3) a simplification creates less cognitive load for the learner. In our case, the goal of building a model is to offer students an opportunity to learn with and from the model. When learning with simulations, learners interact with the model through an interface that enables them to change 
values of input variables and observe the effects of these changes on output variables (see de Jong, 2006a).

Simulation programs can be used as the basis for training of knowledge or skills (or a combination of both). In the case of learning practical skills, transfer to real situations is crucial, so high fidelity is often preferred. High fidelity means that the model in the simulation must be realistic and also that the interface (for both input and output) needs to be close to the real situation (Hays \& Singer, 1989). In some cases, high fidelity can be accomplished by using a physical interface rather than a computer screen. Parker and Myrick (2009), for example, describe high-fidelity human patient simulators that are rapidly becoming part of nursing education. These simulators are embedded in a mannequin that is able to show physiological responses; modern devices can even speak, breathe, and perspire. In this way, a realistic training environment is created, which is required because nurses need to recognize symptoms in real persons.

Realism need not be high at the start of the training; its level may be increased during training in order to avoid overloading students in the beginning (Alessi, 2000). In the case of acquiring more theoretical knowledge (be it more conceptual or procedural), the fidelity requirements for the interface are not that high, although real-world interfaces are sometimes recommended for motivational reasons (de Hoog, de Jong, \& de Vries, 1991). The level of realism of representations could also affect the knowledge that is acquired. Jaakkola, Nurmi, and Veermans (2009) compared two simulation environments on the physics topic of electricity. In one condition only concrete representations were used (bulbs), while in the other there was a transition from concrete to more abstract representations (resistors). The concrete situation was easier for students to learn, but students who could cope with the complexity of the transition condition acquired knowledge that was better transferable to other domains.

Simulations are used for learning in many domains including psychology (Hulshof, Eysink, \& de Jong, 2006), mathematics (Tatar et al., 2008), physics (Wieman, Perkins, \& Adams, 2008), chemistry (Winberg \& Hedman, 2008), biology (Huppert, Lomask, \& Lazarowitz, 2002), and medicine (Wayne et al., 2005). The models involved also vary widely, both in complexity and in content. Law and Kelton (2000) distinguish models according to three dimensions: (1) whether time is one of the variables in the model (i.e., static vs. dynamic models); (2) whether change plays a role in the model (i.e., deterministic vs. stochastic models); and (3) whether the variables in the model can take all values on a scale or vary in only in discrete steps (i.e., continuous vs. discrete models). Although differences in complexity and content may influence the learning process, there are sufficient commonalities across simulations to discuss their affordances for learning in a general way.

In the remainder of this chapter, I provide an historical overview of educational computer simulations, a theoretical framework for learning from computer simulations, and summaries of the current state of research on the effects of incorporating scaffolds that guide learning with computer simulations and on the effects of teaching with computer simulations rather than conventional media. The chapter closes with a discussion of practical and theoretical implications, and an examination of future directions.

\section{HISTORICAL OVERVIEW}

Simulations have long been used in training to avoid risks for the operators (e.g., aviation), subjects (e.g., medicine) or both operators and subjects (e.g., military, business). 
One of the earliest reports on the use of a simulator for learning dates back to the Ruggles orientator (see Jones, 1927) - a device to test pilots on very basic skills. These devices gradually became more sophisticated, with today's flight simulators offering a very high level of functional and physical fidelity. Besides these full-fledged simulators, computerbased simulators have been very popular, beginning from the landmark introduction of Microsoft Flight Simulator in 1979/1980. These relatively inexpensive computer-based simulators have also shown their value for training pilots (see, for an overview, Koonce \& Bramble, 1998).

In medicine, the use of simulators and simulations has a century-long history, but simulators started to enter medical education at a reasonable level only during the second half of the 20th century have. Nowadays a rapid increase in the use of simulators in medical education is underway, ranging from high fidelity simulators to desktop computer-based simulations (Bradley, 2006).

Possibly the longest history of simulation use can be found in the military. Wargames were often used, with the earliest known version, the German Kriegspiel, dating back to the early 19th century. Even before that, the military used sand tables with iconic representations. Nowadays, digital games are dominant and they exist in many variations for professional and private usage (for an overview, see Smith, 2010).

Business games and simulations have a shorter history that dates back to the 1950s. There are many of these games in existence, now using technologies that enable on-line access. However, there is not much research that examines the outcomes of this type of learning, and the research that does exist is not very definitive on the benefits of business games for the acquisition of knowledge (Anderson \& Lawton, 2009; Leemkuil \& de Jong, in press). The lack of supporting evidence may have to do with the fact that games have characteristics that are not favorable for learning; for example, learners in a game have less freedom to act than learners in a simulation, due to the goal they must reach (Leemkuil \& de Jong, in press).

The traditional application areas for the use of computer simulations for training were focused towards practical skills training (e.g., flying, medical diagnosing, waging war, doing business) and no specific guidance for students was built in. In the late 1970s and early 1980s, new systems were developed, often in the form of intelligent tutoring systems which emphasized training of conceptual knowledge along with skills and included forms of student guidance. These simulations also began to involve domains other than the traditional ones sketched above.

Many of these systems had a focus on diagnosis and troubleshooting. SOPHIE, for example, was an environment for teaching electronic troubleshooting skills, but also aimed at acquisition of conceptual knowledge of electronic laws, circuit causality, and the functional organization of particular devices (Brown, Burton, \& de Kleer, 1982). Similarly, QUEST (White \& Frederiksen, 1989) focused on electronic circuit troubleshooting, with central attention for knowledge of underlying models from different perspectives. Also SHERLOCK (Lesgold, Lajoie, Bunzo, \& Eggan, 1992) aimed at troubleshooting skills for electronic devices and provided trainees with individualized feedback. Another system that combined the learning of operational and conceptual knowledge was STEAMER. This system simulated a complex steam propulsion system for large ships (Hollan, Hutchins, \& Weitzman, 1984) and students also had to understand the models underlying this system. Systems such as MACH-III on complex radar devices (Kurland \& Tenney, 1988) and IMTS (Towne et al., 1990) also focused on 
troubleshooting, again with associated conceptual knowledge. A further example of early conceptual simulations for physics education was ARK (Scanlon \& Smith, 1988; Smith, 1986). ARK (Alternate Reality Kit) was a set of simulations on different physics topics (e.g., collisions) that provided students with direct manipulation interfaces. In another field, the MYCIN software was an expert system that contained a large rule base for medical diagnosis, which the GUIDON software took up and augmented with teaching knowledge to make this learning software. A student model was created through an overlay approach and students could receive dedicated feedback on their diagnosis process (Clancey, 1986).

Smithtown was one of the first educational computer simulations that targeted an exclusively conceptual domain (i.e., economic laws) and that included a range of support mechanisms for students (Shute \& Glaser, 1990). In Smithtown, students could explore simulated markets. They could change such input variables as labor costs and population income and observe the effects on output variables such as prices.

Although scaffolds were already present to some degree in the early computer simulation systems cited here, most specifically Smithtown, recent research has shown that learning with simulations is most effective when the student is sufficiently scaffolded (de Jong \& van Joolingen, 1998; Mayer, 2004). Cognitive scaffolds can be integrated with the simulation software or can be provided by the teacher; they can aim at a specific inquiry process (e.g., hypothesis generation) or at the structuring of the entire process. These types of systems are discussed later in this chapter.

\section{THEORETICAL FRAMEWORK}

Why would learning with simulations be better than more traditional expository explanation-based or "on-the-job training" approaches? There are several considerations why simulation-based learning would improve performance, all depending on the goal of learning: conceptual knowledge, skills, or a combination.

When simulations are used to help learners acquire conceptual knowledge, the rationale is that they foster deeper cognitive processing during learning, which in turn leads to deeper learning outcomes (in comparison to direct instruction). In particular, computer simulations are intended to encourage learners to activate relevant prior knowledge (e.g., in thinking of hypotheses) and to actively restructure knowledge (e.g., when data are found that are not consistent with a hypothesis). For example, some theoretical frameworks, which can be traced back to Piaget's original ideas (1976), consider learning with simulations as involving an inquiry cycle consisting of processes such as hypothesis generation, experiment design, data interpretation, and reflection (see Friedler, Nachmias, \& Linn, 1990; de Jong, 2006a). A related approach describes this scientific inquiry as a specific kind of problem solving with associated moves in a problem space, in this case, hypothesis and experiment space (Klahr \& Dunbar, 1988; Klahr \& Simon, 2001).

A second approach that highlights advantages of simulations for conceptual learning is the work on multiple representations (e.g., Ainsworth, 2006; Mayer, 2009). The basic idea behind this approach is that if multiple representations (e.g., graphs, tables, animations, etc.) are offered, translations must be made between these representations, leading to deeper and more abstract knowledge. Simulations often offer multiple representations and these are often also dynamically linked (van der Meij \& de Jong, 2006). In a series of experiments, Kolloffel and colleagues (Kolloffel, de Jong, \& Eysink, 2010; Kolloffel, 
Eysink, de Jong, \& Wilhelm, 2009) found that different combinations of representations have different effects on learning. Their case involved the learning of combinatorics, in which a combination of formulae and text was the most profitable combination of representations for students.

A third, and somewhat different stance is taken by Lindgren and Schwartz (2009) who emphasize the advantages of simulations from the observation that these environments often offer interactive visualizations. These authors show on the basis of more fundamental work that interactive visual information has the advantages over textual information of being more easily remembered, being suitable for showing variation and differences between cases, conveying structure that is not easily depicted in textual information, and giving a more direct experience via manipulations. The advantages of interactive visualizations are supported by research. Studies that compare simulations in which students can make their own choices with an environment where they cannot show an advantage for the action-based form of learning (Trey \& Khan, 2008; Windschitl \& Andre, 1998) although sometimes only on a delayed test (Hulshof, Eysink, Loyens, \& de Jong, 2005). These advantages, however, do not occur when students are left on their own and do not receive support for the inquiry process (Boucheix \& Schneider, 2009). Advantages are also mitigated when the environment is simple and when instructional measures are more dominant than interface characteristics (Swaak, de Jong, \& van Joolingen, 2004).

An important principle for training skills (e.g., in aviation, medicine) in simulated instead of real environments is that this allows students to receive a more extended experience with the task to be learned. Compared to the real world, simulations offer the possibility of introducing situations independent of place and time, of presenting critical situations that may not occur frequently in reality, and of creating situations that would be too expensive or dangerous in reality (Alessi \& Trollip, 2001). The main principle behind this approach is that an element of practice is necessary in the learning of skills. This practicing of skills requires variation in tasks and confrontation with critical tasks (van Merriënboer, 1997); simulations, not having to rely on the natural and possibly rare occurrence of differing and critical situations, offer the best opportunity to effect this. In addition, computer simulations also offer the possibility of augmenting reality by showing features that cannot be seen in reality (Blackwell, Morgan, \& DiGioia, 1998). Further, simulations can help to speed up or slow down tasks so that practice can take place more deliberately and moments of reflection may be built in. Comparisons of simulations to laboratory situations address similar notions (Jaakkola, Nurmi, \& Lehtinen, i press a).

Critics assert that learning with simulations is not effective because the required processes are too demanding for students, leading to cognitive overload (Kirschner, et al., 2006). However, this criticism is directed at unsupported pure discovery and does not apply to learning environments that offer students support for their inquiry processes. This learner support is essential for successful inquiry and thus for learning from computer simulations. The next section outlines this issue and discusses the effectiveness of learning with computer simulations.

\section{CURRENT ISSUES: THE EFFECTIVENESS OF SIMULATION-BASED LEARNING}

One of the central research questions addressed in this chapter is whether simulationbased instruction fosters an effective form of learning. When considering this question, 
it is important to realize that it is not the technology per se that causes learning but rather the instructional method (Clark, 1994). The question of effectiveness also depends on what is being measured (e.g., different types of knowledge, inquiry skills, attitudes) as an outcome of the learning process, and may vary with the students' characteristics. A short overview of research is presented in the following sections. The first section presents studies comparing different versions of basically the same simulation learning environment. Here, for example, different types of scaffolds are compared. The second section presents studies in which completely designed simulation environments are compared to alternative didactic approaches (e.g., expository instruction or on-the-job training).

\section{The Effects of Providing Students with Cognitive Scaffolds}

Work claiming that direct instruction is superior to inquiry learning generally involves unguided inquiry (e.g., Klahr \& Nigam, 2004). What is very clear from the literature is that unguided simulation based learning is not effective (Mayer, 2004). For this reason, contemporary inquiry learning as well as simulation-based learning environments contain all kinds of supports and scaffolds (Hmelo-Silver, Duncan, \& Chinn, 2007). Guided simulations lead to better performance than open simulations (de Jong \& van Joolingen, 1998) and are also experienced by students as being more effective (Winberg \& Hedman, 2008). Several overviews have indicated which types of support are available and how they make learning from simulations effective (Chang, Chen, Lin, \& Sung, 2008; de Jong, 2005, 2006a, 2006b, in press; Fund, 2007; Quintana et al., 2004). In this section, the main conclusions from these overview studies will be summarized, complemented by more recent work. The summary of the different types of support is organized following the main inquiry processes: orientation, hypothesis design, experimentation, and drawing conclusions, along with regulative (planning and monitoring) and reflection processes.

\section{Orientation}

When working with computer simulations, students may need to be supported in identifying the main variables in the domain. Belvedere (Toth, Suthers, \& Lesgold, 2002), for example, is an inquiry environment in which students work with realistic problems, collect data, set hypotheses, etc. An inquiry diagram is available to explore the domain under study. This inquiry diagram is a kind of concept mapping tool dedicated to scientific inquiry. It also functions to relate statements and evidence. Toth et al. (2002) report positive effects on reasoning scores for students using the Belvedere inquiry diagram as compared to students who used simple prose to express their view of the domain. Reid, Zhang, and Chen (2003) studied students who learned with a simulation on buoyancy and provided them with "interpretative support," which consisted of multiple choice questions to activate prior knowledge and to make students think about the variables that played a role in the simulation, together with access to a database of background knowledge. This support had a positive effect on students' intuitive understanding (students' ability to predict effects of changes), which effect was confirmed in a follow-up study (Zhang, Chen, Sun, \& Reid, 2004). Holzinger, Kickmeier-Rust, Wassertheurer, and Hessinger (2009) compared three versions of a course on blood flow for medical students-a text version, a computer simulation and a computer simulation preceded by a short video explaining the main parameters. Students who received the video plus simulation treatment outperformed the simulation only and text groups on a short 
multiple-choice test of conceptual knowledge. The text and the simulation-only groups did not differ in performance.

The use of multiple representations presents a specific case with regard to helping students orient themselves and find the right variables. First of all, students need to be supported in making the right interpretations of visualizations (Ploetzner, Lippitsch, Galmbacher, Heuer, \& Scherrer, 2009; Tsui \& Treagust, 2003), but they also need support in making the correct relations between representations. Wu, Krajcik, and Soloway (2001), for example, worked with a combined modeling and simulation environment for chemistry, more specifically molecular models. In their learning environment they supported students in making references between the different representations by providing them with referential links. A qualitative analysis of the students' results showed that this kind of support helped students to make the correct relation between representations, which also helped them to make adequate translations. Bodemer, Ploetzner, Feuerlein, and Spada (2004), working with a simulation environment in statistics, showed that supporting students in actively relating representations was beneficial for learning. Studying student learning in a multiple representational simulation environment on the physics topic of moment, van der Meij and de Jong (2006) found that helping students to relate representations by dynamic linking (concurrent changes over time), color coding that related similar variables in different representations, and integration of representations led to greater student gains in domain knowledge compared to students for whom relating representations was not supported.

\section{Hypothesis Design}

The creation of hypotheses by students can be supported in different ways. Thinkertools/ Inquiry Island environments, for example, present learners with free text blocks to brainstorm about and to present their hypotheses (White et al., 2002). By using sliders, learners can indicate the degree to which they think their hypothesis is "believable," "related to the question they had," and "testable." Students can also indicate if they have alternative hypotheses. A more specific scaffold for hypothesis generation is the hypothesis scratchpad (Shute \& Glaser, 1990; van Joolingen \& de Jong, 1991). In recent versions of this scratchpad (van Joolingen \& de Jong, 2003), learners can compose hypotheses by filling in if-then statements and by selecting variables and relations to fill in the slots. For each hypothesis, they can indicate whether it was tested or not, and whether the data confirmed the hypothesis. However, the authors found that working with such a scratchpad is not very easy for students. Following work by Njoo and de Jong (1993), Gijlers and de Jong (2009) provided students with complete, pre-defined, hypotheses. They created three experimental groups of collaborating dyads of learners. One group (control) did not receive specific scaffolds, one group had a shared hypothesis scratchpad combined with a chat, and the final group received a large set of propositions about the domain. As an overall result, students in the proposition group outperformed students in the other two groups on a measure of intuitive knowledge. A broad conclusion might be that for beginning students, support in the form of complete hypotheses is more beneficial than having them compose hypotheses themselves.

\section{Experimentation}

There is a range of heuristics that can be used to design "good experiments" (Baker \& Dunbar, 2000) of which the control of variables strategy (CVS, Chen \& Klahr, 1999) is the 
best known (Wilhelm \& Beishuizen, 2003). This strategy implies that only one variable at the time is varied in experiments and the others are kept constant, so that effects can be attributed to that variable that was varied. Kuhn and Dean (2005) showed that even a simple prompt to focus on one variable at a time may help to increase students' performance level. Keselman (2003) had students work with a simulation-based learning environment on a complex domain with multivariable causality (i.e., risks of earthquakes). One group of students received extensive practice on manipulating variables and making predictions, whereas a second group also observed a teacher modeling the design of good experiments. Both groups improved compared to a control group that received no support, but the modeling group improved most on knowledge gained and on skill in designing good experiments. Lin and Lehman (1999) worked with students who learned in a biology simulation learning environment. They provided students with prompts for designing experiments with an emphasis on the control of variables strategy (e.g., "How did you decide that you have enough data to make conclusions?," Lin \& Lehman, 1999, p. 841). These prompts helped students to understand experimental design principles and resulted in better transfer compared to a group of students who received different types of prompts.

Reid et al. (2003) gave students explanations on good experimental procedures and helped students structure their experiments. Overall, they found no effect of this support on a range of measures including intuitive knowledge (on which only a marginal effect was found), transfer, and knowledge integration (how far students had related their new knowledge to existing knowledge and how far they acquired deep principles). A followup study (Zhang et al., 2004) added the nuance of taking learner's reasoning abilities into account. Zhang et al. found that support that aimed at the experimentation behavior of students was most effective for low reasoning ability students, indifferent for high ability students and detrimental for the mid-range ability students. Veermans, van Joolingen, and de Jong (2006) compared two simulation-based learning environments (containing implicit or explicit heuristics for designing experiments) on the physics topic of collision. They found no overall difference between the two conditions on knowledge gained and strategies acquired, but found indications that the explicit condition favored weak students.

\section{Regulation}

One way to support students in regulating their inquiry process is by providing them with an overall structure (Njoo \& de Jong, 1993). In Sci-Wise (Shimoda, White, \& Frederiksen, 2002) and the follow-up Thinkertools/Inquiry Island (White, et al., 2002) the inquiry process was divided into question, hypothesize, investigate, analyze, model, and evaluate. Learners had differently structured tabsheets for each of these tasks and dedicated advisors they could call upon to receive domain independent advice on how to perform a specific inquiry task. Manlove, Lazonder, and de Jong (2009b) report a series of studies on a process coordinator, a tool that structures the inquiry process for students and that helps and prompts student to plan, monitor, and evaluate. Their work shows that these tools stimulate students to plan, but that students are not very much inclined to monitor their work. The studies also indicated a negative relation between use of regulative facilities and students' model scores. The authors make clear that this could be caused by the general character of the tool and that a stronger embedding of the tool in the domain would be necessary. In a similar vein, Chang et al. (2008) found that 
providing students with step-by-step guidance in a simulation environment on optics was less effective than giving them detailed experimentation hints and hypothesis support. Providing students with sets of assignments or exercises that give them ideas for questions to ask and variables to manipulate and that give structure in the inquiry process is a very powerful form of support. This conclusion is substantiated by many studies with both an experimental character (Swaak \& de Jong, 2001) and more practice-oriented work (Adams et al., 2008). A specific issue here is that students are not greatly inclined to use facilities that are offered to them, especially in connection with monitoring (Manlove, Lazonder, \& de Jong, 2007).

\section{Reflection}

A number of studies have systematically examined the effect of reflection scaffolds, as in the work by Lin and Lehman (1999) cited above. Davis (2000) examined the effects of activity and self-monitoring prompts on project progress and knowledge integration, in the context of the KIE (Knowledge Integration Environment) inquiry environment. Activity prompts encouraged students to reflect on the content of their activities. An activity prompt may, for example, "ask students to justify their decision or write a scientific explanation of a decision” (Davis, 2000, p. 822). Self-monitoring prompts activated students to express their own planning and monitoring by giving them sentence openers to complete. A sample prompt would be "Pieces of evidence or claims in the article we didn't understand very well included ..." (Davis, 2000, p. 824). Three studies were conducted in the domain of heat and temperature. Two studies compared conditions with different types of reflection prompts, while the third study looked deeper into students' reactions to prompts. Overall, self-monitoring prompts helped more with creating a well-connected conceptual understanding (knowledge integration) than activity prompts, although Davis also concluded that similar prompts led to quite different reactions from different learners. Zhang et al. (2004) performed a study in which they gave learners reflective support, i.e., support that “increases learners' self-awareness of the learning processes and prompts their reflective abstraction and integration of their discoveries" (p. 270). The learning environment centered around a simulation on floating and sinking of objects. The treatment consisted of: (1) showing the students their inquiry processes (goals of experiments, predictions, and conclusions); (2) reflection notes that students had to fill in asking them to reflect on the experiment; and (3) a fillin form after the experiment that asked students to think over the process they had gone through and the discoveries they had made. Students who received this type of evaluation support outperformed students who did not receive this support on a number of performance measures.

Wichmann and Leutner (2009) studied the effects of reflective prompts in the context of a simulation on photosynthesis. These prompts were related to stating hypotheses, interpreting results, and thinking of new research questions. The students who received these prompts outperformed students from two control groups who did not receive these prompts or who only received explanation prompts. These results emerged for both a knowledge test and a scientific reasoning test.

\section{Conclusions on the Use of Scaffolds}

The overall conclusion from studies that evaluated scaffolding for simulations is that support helps. Even when different kinds of composite support are compared and 
sometimes subtle differences between support measures are found, it is clear that supported students outperform unsupported students (Fund, 2007). As a coarse summary, it can be stated that students need support in identifying relevant variables, that hypotheses could best be provided in a "readymade" way, that training on experimentation heuristics (especially CVS) is fruitful but only for students of poor reasoning ability, that providing students with a general structure for the inquiry process can be helpful but that it should be made domain-specific, such as in the form of a set of more concrete assignments, and that students need to be prompted for reflection. However, most of the results are based on single studies, and it remains to be seen what support students need when they have a longer term experience with simulation based inquiry learning. Such a situation might lay the basis for fading the scaffolding at some point so that over time a good balance can be reached between taking the inquiry out of students' hands and preserving the inquiry character of the learning process.

\section{Simulation-Based Learning Compared to Other Instructional Approaches}

There are many studies showing that learning with scaffolded computer simulations may help students to overcome misconceptions (e.g., Meir, Perry, Stal, Maruca, \& Klopfer, 2005; Monaghan \& Clement, 1999). A next step then is to compare these results to learning from direct instruction or other didactic approaches. Such work has been limited, but there is an emerging set of studies that present large scale comparative evaluations of simulation-based learning. In these cases the simulation is often embedded in a larger instructional arrangement and it includes a composite of different scaffolds, which means that no specific data on individual scaffolds are available for these largescale evaluations,. There is also a set of studies that compares simulation-based learning to learning in the real laboratory.

\section{Simulations vs. Traditional Teaching}

One of the first examples of such a large-scale evaluations concerns Smithtown, a supportive simulation environment in the area of economics, which underwent a large-scale evaluation with a total of 530 students. Results showed that after 5 hours of working with Smithtown, students reached a degree of micro-economics understanding that would require approximately 11 hours of traditional teaching (Shute \& Glaser, 1990).

White and Frederiksen (1998) describe the ThinkerTools Inquiry Curriculum, a simulation-based learning environment on the physics topic of force and motion. In the ThinkerTools software, students are guided through a number of inquiry stages that include experimenting with the simulation, constructing physics laws, critiquing each other's laws, and reflecting on the inquiry process. ThinkerTools was implemented in 12 classes with approximately 30 students each. Students worked daily with ThinkerTools over a period of a little more than 10 weeks. A comparison of the ThinkerTools students with students in a traditional curriculum showed that the ThinkerTools students performed significantly better on a conceptual test ( $68 \%$ vs. $50 \%$ correct).

With regard to large-scale comparisons in the domain of science, Hickey, Kindfield, Horwitz, and Christie (2003) assessed the effects of the introduction of a simulationbased inquiry environment on the biology topic of genetics (GenScope). In GenScope, students can manipulate genetic information at different levels: DNA, chromosomes, cells, organisms, pedigrees, and populations. A large-scale evaluation was conducted involving 31 classes ( 23 experimental, 8 comparison) taught by 13 teachers, and a few 
hundred students in total. Overall, the evaluation results showed better performance by the GenScope classes compared to the traditional classes on tests measuring genetic reasoning. A follow-up study with two experimental classes and one comparison class also showed significantly higher gains for the two experimental classes on a reasoning test, with a higher gain for students from the experimental group in which more investigation exercises were offered. Linn, Lee, Tinker, Husic, and Chiu (2006) evaluated modules created in the TELS (Technology-Enhanced Learning in Science) center. These modules are inquiry-based and contain simulations (e.g., on the functioning of airbags). Over a sample of 4328 students and 6 different TELS modules, an overall effect size of 0.32 was observed in favor of the TELS subjects over students following a traditional course for items measuring how well students' knowledge was integrated.

The domain of mathematics has also been an area for large-scale comparisons. Eysink et al. (2009) compared four technology-based learning environments on the same topic of probability theory. These environments were based on hypermedia learning, observational learning, explanation based learning, and simulation based learning. The study involved a total of 624 participants who all received the same knowledge tests with items on situational, intuitive, procedural, and conceptual knowledge. Overall results show that the explanation-based learning environment led to the highest performance, followed by the simulation-based learning environment and then the observational and hypermedia learning environments. However, explanation-based learning was the least efficient (in terms of achievements related to learning time) of the four approaches, hypermedia learning and observational learning the most efficient, and simulationbased learning held an intermediate position.

Tatar et al. (2008) compared performances of a few hundred students and 25 teachers using a SIMCALC-based curriculum vs. a standard curriculum. The SIMCALC curriculum was primarily based on mathematic simulations. Results showed large advantages for the SIMCALC students on mathematical knowledge; the teachers' knowledge in the SIMCALC classes also improved significantly over that of the teachers in the standard curriculum groups. De Jong, Hendrikse, and van der Meij (in press) compared a simulation-based mathematics course to traditional instruction. Over 12 weeks of lessons, students followed either their traditional regular course or an experimental course in which simulation-based exercises were used in conjunction with the book. The data from a total of 418 students from 20 classes could be analyzed. Results indicate that students from both groups score similarly well overall on a post-test, but students from the traditional lectures score especially high on procedural knowledge, while the simulation-based students tend to get better scores on conceptual items. In the related area of statistics (correlations) Liu, Lin, and Kinshuk (2010) found that students using simulation-based training clearly outperformed students who followed a lecture-based approach in repairing misconceptions and on tests measuring understanding.

\section{Simulations Compared to Laboratories}

There is now a growing number of studies comparing learning from simulations to learning in real laboratories. These studies can be divided into two groups. The first group compares a simulation with a real laboratory. Here, advantages for the simulation are found in effectiveness and/or efficiency. The second group compares real laboratories and some combination of simulations and laboratories. Overall, students who 
receive a combination outperform the pure laboratory students. These results all refer to measures of conceptual knowledge.

Chang, Chen, Lin, and Sung (2008) compared learning of the physics topic of optics with three simulation-based environments (that included support in the form of experimentation prompts and hypothesis support) with learning in a laboratory, and concluded that students in all three simulation environments scored better on a test of conceptual knowledge than the laboratory students. Huppert et al. (2002) compared a group of students who followed a combination of traditional lecture and laboratory-based instruction on microbiology with a group who learned with a computer simulation integrated in the laboratory. They found better scores on a conceptual test for the simulation group and some advantages for the simulation group on acquiring science process skills. Bell and Trundle (2008) compared the conceptual knowledge of moon phases for students who gathered data by observing the moon itself and students who worked with a simulation and found large advantages for the simulation group.

A number of other studies found no differences in outcomes between simulated environments and real laboratories, but in these cases simulation-based training was more efficient. Klahr, Triona, and Williams (2007) compared students' performance in a simulated and a real environment in which students had to design a car. They found no difference between the two conditions in resulting knowledge about factors contributing to the car's performance. Triona and Klahr (2003) compared students' mastery of the control of variables strategy in physics domains after learning with a simulation or with physical material and found no differences.

In a somewhat different but comparable setting, Winn et al. (2006) compared the knowledge gained by students who gathered data on oceanographic knowledge (e.g., tides) on a trip on a real boat with students learning from a simulation. Overall both groups scored equally well, with some advantages for the simulation group on two subtests measuring conceptual and structural knowledge. Zacharia and Constantinou (2008) compared two groups of students working in either a physical or a virtual laboratory on heat and temperature; both groups learned equally well. Zacharia and Olympiou (in press) compared a condition where the instruction centered around lectures and textbooks with four experimental conditions in which over 200 students learned about the physics topic of heat and temperature using either a physical laboratory, a simulation, or combinations of a physical laboratory and simulation. All courses were inquirybased, followed the same instructional principles and lasted 15 weeks. No differences between the four experimental conditions were found on a test measuring conceptual knowledge, but a clear difference in favor of these conditions over the more traditional approach was evident.

A second group of studies found advantages for the combination of simulated and real environments. Akpan and Andre (2000) compared learning the skill of dissecting a frog, and found that students who worked with a simulation alone or with a simulation preceding actual dissection outperformed students performing the hands-on dissection alone or preceding a simulation on a test measuring knowledge of frog anatomy. Zacharia and Anderson (2003) compared learning with a simulation before the real laboratory and with the real laboratory only (and additional textbook material). The domains included were the physics topics of mechanics, optics, and thermal physics. Results showed that adding a simulation to the laboratory helped to increase scores on a conceptual test which required making predictions and giving explanations. 
Zacharia (2007) compared two groups of learners where one group learned about electrical circuits in a virtual environment and the other started in a real environment and then moved to a virtual environment. The second group scored better than the first on a conceptual test; this difference could be attributed to the specific parts of the curriculum for which one group learned in the virtual environment and the other in the laboratory environment. Similar results were found by Zacharia, Olympiou, and Papaevripidou (2008). Jaakkola and Nurmi (2008), studying the learning of electrical circuits, found that a succession of a simulated and a real environment led to better performance than either a simulated or a laboratory environment alone. The advantage of combining simulated and real environments was confirmed in another study where video data were analyzed to try to explain why this was the case (Jaakkola et al., in press z.). From the video data the authors concluded that students focus on different issues in the simulated and real laboratories and this helps them to create a complete view. In a follow-up study (Jaakkola, Nurmi, \& Veermans, in press $b$ ) the advantages of the combination of real and virtual laboratories against a simulation alone were confirmed.

\section{Conclusions on the Effectiveness of Simulation-Based Learning}

In summary, and as a very general conclusion, large-scale evaluations of carefully designed simulation-based learning environments show advantages of simulations over traditional forms of expository learning and over laboratory classes. These results may become slightly more nuanced when we look at the different types of learning outcomes. Most studies focused on conceptual (intuitive) knowledge. For example, Reid et al. (2003) found the largest differences between conditions on a test of intuitive knowledge. Day and Goldstone (2009), studying the transfer abilities of students learning with a simulation on oscillatory movement, concluded that any transfer that occurred was based on implicit knowledge. Making this knowledge more explicit by asking learners to seek for rules even reduced the level of transfer. This work shows that simulation-based learning may be very well suited for gaining intuitive knowledge.

There are, however, other relevant forms of domain knowledge that may be stimulated by learning with simulations such as inquiry skills, nature of science, and attitudes towards science. These areas, although having already received attention in work cited above, need more research, because there are indications that learning with simulations may have impact on such aspects as systems thinking (Evagorou, Korfiatis, Nicolaou, \& Constantinou, 2009).

A second shortcoming of this body of work is that individual differences are not often taken into account. For example, gender is scarcely considered, although there is work suggesting that simulations are more favorable for boys than for girls (e.g.) de Jong, et al., in press; Holzinger, et al., 2009). Other characteristics such as prior knowledge or spatial ability also seem to influence learning with simulations or the effects of scaffolds. Based on a qualitative analysis of students working with a computer simulation on electrochemistry, for example, Liu, Andre, and Greenbowe (2008) found that students with higher prior knowledge provided more verbal explanations during their work than students with lower prior knowledge.

Liu et al. (2008) speculate that a highly structured environment is more suited for lower prior knowledge students, whereas those with higher prior knowledge profit more from an open environment. There are indications that prior knowledge is especially important when the simulations are highly interactive (i.e., they have many variables to 
manipulate; (Park, Lee, \& Kim, 2009)). An example of the influence of spatial ability is seen in work by Urhahne, Nick, and Schanze (2009), who found that spatial ability had a strong influence on the level of conceptual knowledge that students gained from twoand three-dimensional simulations in chemistry. Finally, students also need sufficient regulative skills to be able to work in simulation-based learning environments (Hsu \& Thomas, 2002).

\section{Practical Implications}

Overall, results encourage the use of computer simulations in the classroom. At this time, however, we do not see extensive use of simulations in daily school practice. Upscaling and implementing simulations in actual teaching practices are obviously still a challenge. There are several reasons for this, which have mainly to do with technical and didactic issues. First, schools are often not prepared for the technical challenges of introducing software into their curriculum. In addition, software is not always stable enough and well enough tested to survive in the classroom climate. Software developed in a safe laboratory environment needs a few more rounds of testing and debugging before it can be used safely in actual classrooms.

Further, most available software that comes from research projects has no maintenance guarantee, which means that schools are not sure that what runs today will run next year as well. Second, for the didactic issues, most simulations, including the ones described in this chapter, are not developed in alignment with the method and curriculum used in the schools. Simulations as available on the web or off the shelf typically do not have the instructional scaffolding that was seen in this chapter to be required to ensure effectiveness of the simulation software. In addition, working with simulations often takes more time (compared to direct instruction), and teachers do not have that additional time. Teachers also need also to be trained, not only on technical skills but also on didactic techniques such as inquiry learning. This often does not happen. There is a clear need for commercial publishers and teacher training departments to take up these challenges.

\section{CONCLUSION AND FUTURE DIRECTIONS}

This chapter gave an overview of advantages and disadvantages of simulation-based learning. The overall conclusion is that simulation-based inquiry learning can be effective if the learners have adequate knowledge and skills to work in such an open and demanding environment and if they are provided with the appropriate scaffolds and tools. In those cases where adequate support is given, simulation-based learning may lead to better results than direct instruction or laboratory based exercises. This conclusion fits within the general conclusion from a meta-analysis of 138 studies that inquiry learning leads to better learning results than direct instruction (Minner, Levy, \& Century, in press).

The discussion on the relative effectiveness of direct instruction vs. simulation-based learning (or inquiry learning in general) will remain a lively one (see e.g., Kirschner et al., 2006; Klahr \& Nigam, 2004; Kuhn, 2007; Kuhn \& Dean, 2005). This discussion, however, will have no final "winner." There are surely domains and/or learners for which a more direct approach is favorable (Kirschner et al., 2006) and even within domains and learners a variation in instructional methods covering both inquiry approaches and direct instruction might be necessary. The better question is, for what goals and for what 
learners in what circumstances is what instructional approach the best approach (Schwartz \& Bransford, 1998)? The central issue here is what we want students to learn (Kuhn, 2007). In that respect it is noteworthy that the vast majority of the work has concentrated on the effects of simulation-based learning on conceptual (or intuitive) knowledge. There are some examples of work that takes other knowledge aspects (e.g., inquiry skills) into account, but more attention to other types of knowledge than just conceptual knowledge is one of the necessary future directions for the field of learning with computer simulations.

The relative effectiveness of instructional approaches may also depend on the time frame taken into account. Dean and Kuhn (2007), for example, found that when introducing a more extended time frame (10 weeks) and several moments of delayed testing, direct instruction loses its initial advantages and inquiry learning takes over results, which contradicts the results presented by Klahr and Nigam (2004). Students normally lack extensive experience with inquiry learning and some inquiry skills need longer exposure to be developed (Kuhn, Black, Keselman, \& Kaplan, 2000). There are indications from more prolonged work (e.g., Fund, 2007, that lasted over six months) that the effects of scaffolds increase over time. Related work on inquiry learning that is not simulation-based (Sadeh \& Zion, in press) shows that effects may only appear after an extended experience with this form of learning. Studies that use a single shot evaluation may therefore not do justice to inquiry environments; more work that looks at students over a longer period of time is necessary.

A promising road for research and development is collaborative learning with simulations. Studies have shown the potential advantages of doing inquiry with simulations in a collaborative way (Gijlers \& de Jong, 2009; Kolloffel, Eysink, \& de Jong, submitted; Manlove, Lazonder, \& de Jong, 2009a) and more research is needed on identifying conditions that optimize confrontations of opinions between students, on how to design shared representations and on tools and scaffolds specifically geared towards collaborative inquiry with simulations.

An interesting technological innovation is the addition of sensory augmentations to a simulation. Minogue and Jones (2009) studied the effects of adding such a haptic device to a simulation in the domain of cell biology which simulated transport through a cell membrane. This haptic device enabled students to feel the forces that accompanied transport of substances through the cell membrane. Results showed that learners using the haptic version of the simulation reached higher levels of understanding compared to students who had no access to the haptic device. Tolentino et al. (2009) and Birchfield and Megowan-Romanowicz (2009) describe a similar approach in SMALLlab, a simulation environment in which students engage in haptic and auditory experiences through sensory peripherals.

As discussed in this chapter, scaffolds generally are static, in the sense that they do not adapt to developing characteristics of the students. Ideally, scaffolds would only be launched as they are needed by students and scaffolds would adapt (e.g., fade) to the evolving knowledge and skills of learners. An adequate on-line analysis of student knowledge and characteristics is necessary to create such adaptive systems. New techniques, sometimes based on educational data-mining, that enable this are now being developed (Bravo, van Joolingen, \& de Jong, 2006, 2009).

A final development that needs further research is the embedding of simulations in more extensive environments in which students are invited to create things. Objects that 
can be constructed are, for example, computer models (Hestenes, 1987; Pata \& Sarapuu, 2006), physical objects and artefacts (Crismond, 2001), drawings (Hmelo, Holton, \& Kolodner, 2000), and concept maps (Novak, 1990). Simulations can then be used to inform the creation of these objects and the object itself can be tested against simulation data (de Jong \& van Joolingen, 2007).

Simulations play a specific role in education because they allow student actions (i.e., fast interactions with complicated models) that often are hard or impossible to be realized in another way. This chapter showed that scaffolded simulations may form the basis of effective forms of teaching. New developments including adaptive support and the combination with other affordances such as modelling techniques may further enhance the significance of simulations for learning.

\section{REFERENCES}

Adams, W. K., Reid, S., LeMaster, R., McKagan, S. B., Perkins, K. K., Dubson, M., et al. (2008). A study of educational simulations, part I: Engagement and learning. Journal of Interactive Learning Research, 19, 397-419.

Ainsworth, S. (2006). Deft: A conceptual framework for considering learning with multiple representations. Learning and Instruction, 16, 183-198.

Akpan, J. P., \& Andre, T. (2000). Using a computer simulation before dissection to help students learn anatomy. Journal of Computers in Mathematics and Science Teaching, 19, 297-313.

Alessi, S. M. (2000). Simulation design for training and assessment. In J. H.F. O’Neil, \& D. H. Andrews (Eds.), Aircrew training and assessment (pp. 197-222). Mahwah, NJ: Lawrence Erlbaum Associates.

Alessi, S. M., \& Trollip, S. R. (2001). Multimedia for learning; methods and development (3rd ed.). Boston: Allyn and Bacon.

Anderson, P. H., \& Lawton, L. (2009). Business simulations and cognitive learning: Developments, desires, and future directions. Simulation Gaming, 40, 193-216.

Baker, L. M., \& Dunbar, K. (2000). Experimental design heuristics for scientific discovery: The use of "baseline" and "known standard" controls. International Journal of Human-Computer Studies, 53, 335-349.

Bell, R. L., \& Trundle, K. C. (2008). The use of a computer simulation to promote scientific conceptions of moon phases. Journal of Research in Science Teaching, 45, 346-372.

Birchfield, D., \& Megowan-Romanowicz, C. (2009). Earth science learning in SMALLlab: A design experiment for mixed reality. International Journal of Computer-Supported Collaborative Learning, 4, 403-421.

Blackwell, M., Morgan, F., \& DiGioia, A. M. (1998). Augmented reality and its future in orthopaedics Clinical Orthopaedics and Related Research, 354, 111-122.

Bodemer, D., Ploetzner, R., Feuerlein, I., \& Spada, H. (2004). The active integration of information during learning with dynamic and interactive visualisations. Learning and Instruction, 14, 325-341.

Boucheix, J. M., \& Schneider, E. (2009). Static and animated presentations in learning dynamic mechanical systems. Learning and Instruction, 19, 112-127.

Bradley, P. (2006). The history of simulation in medical education and possible future directions. Medical Education, 40, 254-262.

Bravo, C., van Joolingen, W. R., \& de Jong, T. (2006). Modeling and simulation in inquiry learning: Checking solutions and giving intelligent advice. Simulation: Transactions of the Society for Modeling and Simulation International, 82, 769-784.

Bravo, C., van Joolingen, W. R., \& de Jong, T. (2009). Using co-lab to build system dynamics models: Students' actions and on-line tutorial advice. Computers \& Education, 53, 243-251.

Brown, J. S., Burton, R. R., \& de Kleer, J. (1982). Pedagogical, natural language and knowledge engineering techniques in Sophie I, II, and III. In D. Sleeman, \& J. S. Brown (Eds.), Intelligent tutoring systems (pp. 227-282). London: Academic Press.

Chang, K. E., Chen, Y. L., Lin, H. Y., \& Sung, Y. T. (2008). Effects of learning support in simulation-based physics learning. Computers \& Education, 51, 1486-1498.

Chen, Z., \& Klahr, D. (1999). All other things being equal: Acquisition and transfer of the control of variables strategy. Child Development, 70, 1098-1120.

Clancey, W. J. (1986). From guidon to neomycin and heracles in twenty short lessons: Orn final report 19794985. AI Magazine, 7, 40-60.

Clark, R. E. (1994). Media will never influence learning. Educational Technology, Research and Development, 42, 21-29. 
Crismond, D. (2001). Learning and using science ideas when doing investigate-and-redesign tasks: A study of naive, novice, and expert designers doing constrained and scaffolded design work. Journal of Research in Science Teaching, 38, 791-820.

Davis, E. A. (2000). Scaffolding students' knowledge integration: Prompts for reflection in KIE. International Journal of Science Education, 22, 819-837.

Day, S. B., \& Goldstone, R. L. (2009). Analogical transfer from interaction with a simulated physical system. Paper presented at the Thirty-First Annual Conference of the Cognitive Science Society, Amsterdam.

Dean, D., \& Kuhn, D. (2007). Direct instruction vs. discovery: The long view. Science Education, 91, 384-397.

de Hoog, R., de Jong, T., \& de Vries, F. (1991). Interfaces for instructional use of simulations. Education \& Computing, 6, 359-385.

de Jong, T. (2005). The guided discovery principle in multimedia learning. In R. E. Mayer (Ed.), Cambridge handbook of multimedia learning (pp. 215-229). Cambridge: Cambridge University Press.

de Jong, T. (2006a). Computer simulations: Technological advances in inquiry learning. Science, 312, 532-533.

de Jong, T. (2006b). Scaffolds for computer simulation based scientific discovery learning. In J. Elen, \& R. E. Clark (Eds.), Dealing with complexity in learning environments (pp. 107-128). London: Elsevier Science Publishers.

de Jong, T. (in press). Technology supports for acquiring inquiry skills. In B. McGaw, E. Baker, \& P. Peterson (Eds.), International encyclopedia of education. Oxford: Elsevier.

de Jong, T., Hendrikse, H. P., \& van der Meij, H. (in press). Learning mathematics through inquiry; a large scale evaluation. In M. Jacobson, \& P. Reimann (Eds.), Designs for learning environments of the future: International perspectives from the learning sciences. Berlin: Springer Verlag.

de Jong, T., \& van Joolingen, W. R. (1998). Scientific discovery learning with computer simulations of conceptual domains. Review of Educational Research, 68, 179-202.

de Jong, T., \& van Joolingen, W. R. (2007). Model-facilitated learning. In J. M. Spector, M. D. Merrill, J. J. G. van Merriënboer, \& M. P. Driscoll (Eds.), Handbook of research on educational communication and technology (3rd ed., pp. 457-468). Hillsdale, NJ: Lawrence Erlbaum.

Evagorou, M., Korfiatis, K., Nicolaou, C., \& Constantinou, C. (2009). An investigation of the potential of interactive simulations for developing system thinking skills in elementary school: A case study with fifth-graders and sixth-graders. International Journal of Science Education, 31, 655-674.

Eysink, T. H. S., de Jong, T., Berthold, K., Kollöffel, B., Opfermann, M., \& Wouters, P. (2009). Learner performance in multimedia learning arrangements: An analysis across instructional approaches. American Educational Research Journal, 46, 1107-1149.

Friedler, Y., Nachmias, R., \& Linn, M. C. (1990). Learning scientific reasoning skills in microcomputer-based laboratories. Journal of Research in Science Teaching, 27, 173-191.

Fund, Z. (2007). The effects of scaffolded computerized science problem-solving on achievement outcomes: A comparative study of support programs. Journal of Computer Assisted Learning, 23, 410-424.

Gijlers, H., \& de Jong, T. (2009). Sharing and confronting propositions in collaborative inquiry learning. Cognition and Instruction, 27, 239-268.

Hays, R. T., \& Singer, M. J. (1989). Simulation fidelity in training system design. New York: Springer-Verlag.

Hestenes, D. (1987). Towards a modeling theory of physics instruction. American Journal of Physics, 55, 440-454.

Hickey, D. T., Kindfield, A. C. H., Horwitz, P., \& Christie, M. A. (2003). Integrating curriculum, instruction, assessment, and evaluation in a technology-supported genetics environment. American Educational Research Journal, 40, 495-538.

Hmelo, C. E., Holton, D. L., \& Kolodner, J. L. (2000). Designing to learn about complex systems. Journal of the Learning Sciences, 9, 247-298.

Hmelo-Silver, C. E., Duncan, R. G., \& Chinn, C. A. (2007). Scaffolding and achievement in problem-based and inquiry learning: A response to Kirschner, Sweller, and Clark (2006). Educational Psychologist, 42, 99-107.

Hollan, J. D., Hutchins, E. L., \& Weitzman, L. (1984). Steamer: An interactive inspectable simulation-based training system. AI Magazine, 5, 15-27.

Holzinger, A., Kickmeier-Rust, M. D., Wassertheurer, S., \& Hessinger, M. (2009). Learning performance with interactive simulations in medical education: Lessons learned from results of learning complex physiological models with the haemodynamics simulator. Computers \& Education, 52, 292-301.

Hsu, Y.-S., \& Thomas, R. A. (2002). The impacts of a web-aided instructional simulation on science learning. International Journal of Science Education, 24, 955-979.

Hulshof, C. D., Eysink, T. H. S., \& de Jong, T. (2006). The ZAP project: Designing interactive computer tools for learning psychology. Innovations in Education \& Teaching International, 43, 337-351.

Hulshof, C. D., Eysink, T. H. S., Loyens, S., \& de Jong, T. (2005). ZAPS: Using interactive programs for learning psychology. Interactive Learning Environments, 13, 39-53. 
Huppert, J., Lomask, S. M., \& Lazarowitz, R. (2002). Computer simulations in the high school: Students' cognitive stages, science process skills and academic achievement in microbiology. International Journal of Science Education, 24, 803-821.

Jaakkola, T., \& Nurmi, S. (2008). Fostering elementary school students' understanding of simple electricity by combining simulation and laboratory activities. Journal of Computer Assisted Learning, 24, 271-283.

Jaakkola, T., Nurmi, S., \& Lehtinen, E. (in press a). Conceptual change in learning electricity: On the role of virtual and concrete external representations. In L. Verschaffel, E. de Corte, T. de Jong, \& J. Elen (Eds.), Use of external representations in reasoning and problem solving $\mathrm{D}_{\mathrm{\Sigma}}$ New York: Routledge.

Jaakkola, T., Nurmi, S., \& Veermans, K. (2009). Comparing the effectiveness of semi-concrete and concreteness fading computer-simulations to support inquiry learning. Paper presented at the EARLI conference.

Jaakkola, T., Nurmi, S., \& Veermans, K. (in press-b). A comparison of students' conceptual understanding of electric circuits in simulation only and simulation-laboratory contexts. Journal of Research in Science Teaching.

Jones, G. M. (1927). Are you fit to drive an airplane? The Science News-Letter, 12, 113-120.

Keselman, A. (2003). Supporting inquiry learning by promoting normative understanding of multivariable causality. Journal of Research in Science Teaching, 40, 898-921.

Kirschner, P. A., Sweller, J., \& Clark, R. E. (2006). Why minimally guided instruction does not work. Educational Psychologist, 41, 75-86.

Klahr, D., \& Dunbar, K. (1988). Dual space search during scientific reasoning. Cognitive Science, 12, 1-48.

Klahr, D., \& Nigam, M. (2004). The equivalence of learning paths in early science instruction: Effects of direct instruction and discovery learning. Psychological Science, 15, 661-668.

Klahr, D., \& Simon, H. A. (2001). What have psychologists (and others) discovered about the process of scientific discovery? Current Directions in Psychological Science 10, 75-79.

Klahr, D., Triona, L. M., \& Williams, C. (2007). Hands on what? The relative effectiveness of physical versus virtual materials in an engineering design project by middle school children. Journal of Science Teaching, 44 , 183-203.

Kolloffel, B., de Jong, T., \& Eysink, T. H. S. (2010). The influence of learner-generated domain representations on learning combinatorics and probability theory. Computers in Human Behavior, 26, 1-11.

Kolloffel, B., Eysink, T., \& de Jong, T. (submitted). Do representational tools support understanding in combinatorics instruction? Comparing effects in collaborative and individual learning settings.

Kolloffel, B., Eysink, T. H. S., de Jong, T., \& Wilhelm, P. (2009). The effects of representational format on learning combinatorics from an interactive computer-simulation. Instructional Science, 37, 503-517.

Koonce, J. M., \& Bramble, W. J. (1998). Personal computer-based flight traing devices. The International Journal of Aviation Psychology, 8, 277-292.

Kuhn, D. (2007). Is direct instruction an answer to the right question? Educational Psychologist, 47, 109-113.

Kuhn, D., Black, J., Keselman, A., \& Kaplan, D. (2000). The development of cognitive skills to support inquiry learning. Cognition and Instruction, 18, 495-523.

Kuhn, D., \& Dean, D. (2005). Is developing scientific thinking all about learning to control variables? Psychological Science, 16, 866-870.

Kurland, L., \& Tenney, Y. (1988). Issues in developing an intelligent tutor for a real-world domain: Training in radar mechanics. In J. Psotka, L. D. Massey, \& S. Mutter (Eds.), Intelligent tutoring systems: Lessons learned (pp. 59-85). Hillsdale, NJ: Lawrence Erlbaum Associates.

Law, A. M., \& Kelton, W. D. (2000). Simulation modelling and analysis (3rd ed.). New York: McGraw-Hill.

Leemkuil, H., \& de Jong, T. (in press). Instructional support in games. In S. Tobias, \& D. Fletcher (Eds.), Can computer games be used for instruction? New York: Routledge.

Lesgold, A., Lajoie, S., Bunzo, M., \& Eggan, G. (1992). SHERLOCK: A coached practice environment for an electronics troubleshooting job. In J. H. Larkin, \& R. W. Chabay (Eds.), Computer-assisted instruction and intelligent tutoring systems: Shared goals and complementary approaches (pp. 201-239). Hillsdale, NJ: Erlbaum.

Lin, X., \& Lehman, J. D. (1999). Supporting learning of variable control in a computer-based biology environment: Effects of prompting college students to reflect on their own thinking. Journal of Research in Science Teaching, 36, 837-858.

Lindgren, R., \& Schwartz, D. (2009). Spatial learning and computer simulations in science. International Journal of Science Education, 31, 419-438.

Linn, M. C., Lee, H.-S., Tinker, R., Husic, F., \& Chiu, J. L. (2006). Teaching and assessing knowledge integration in science. Science, 313, 1049-1050.

Liu, H., Andre, T., \& Greenbowe, T. (2008). The impact of learners' prior knowledge on their use of chemistry computer simulations: A case study. Journal of Science Education and Technology, 17, 466-482.

Liu, T. C., Lin, Y. C., \& Kinshuk. (2010). The application of simulation-assisted learning statistics (SALS) for correcting misconceptions and improving understanding of correlation. Journal of Computer Assisted Learning, 9999. 
Manlove, S., Lazonder, A. W., \& de Jong, T. (2007). Software scaffolds to promote regulation during scientific inquiry learning. Metacognition \& Learning, 2, 141-155.

Manlove, S., Lazonder, A. W., \& de Jong, T. (2009a). Collaborative versus individual use of regulative software scaffolds during scientific inquiry learning. Interactive Learning Environments, 17, 105-117.

Manlove, S., Lazonder, A. W., \& de Jong, T. (2009b). Trends and issues of regulative support use during inquiry learning: Patterns from three studies. Computers in Human Behavior, 25, 795-803.

Mayer, R. E. (2004). Should there be a three-strikes rule against pure discovery learning? American Psychologist, $59,14-19$.

Mayer, R. E. (2009). Multimedia learning (2nd ed.). New York: Cambridge University Press.

Meir, E., Perry, J., Stal, D., Maruca, S., \& Klopfer, E. (2005). How effective are simulated molecular-level experiments for teaching diffusion and osmosis? Cell Biology Education, 4, 235-248.

Minner, D. D., Levy, A. J., \& Century, J. (in press)__lnquiry-based science instruction: What is it and does it matter? Results from a research synthesis years 1984 to 2002. Journal of Research in Science Teaching.

Minogue, J., \& Jones, G. (2009). Measuring the impact of haptic feedback using the solo taxonomy. International Journal of Science Education, 31, 1359-1378.

Monaghan, J. M., \& Clement, J. (1999). Use of a computer simulation to develop mental simulations for understanding relative motion concepts. International Journal of Science Education, 21, 921-944.

Njoo, M., \& de Jong, T. (1993). Exploratory learning with a computer simulation for control theory: Learning processes and instructional support. Journal of Research in Science Teaching, 30, 821-844.

Novak, J. D. (1990). Concept mapping: A useful tool for science education. Journal of Research in Science Teaching, 27, 937-949.

Papert, S. (1980). Mindstorms: Children, computers, and powerful ideas. New York: Basic Books.

Park, S. I., Lee, G., \& Kim, M. (2009). Do students benefit equally from interactive computer simulations regardless of prior knowledge levels? Computers \& Education, 52, 649-655.

Parker, B. C., \& Myrick, F. (2009). A critical examination of high-fidelity human patient simulation within the context of nursing pedagogy. Nurse Education Today, 29, 322-329.

Pata, K., \& Sarapuu, T. (2006). A comparison of reasoning processes in a collaborative modelling environment: Learning about genetics problems using virtual chat. International Journal of Science Education, 28, 13411368.

Piaget, J. (1976). The grasp of consciousness: Action and concept in the young child. Cambridge, MA: Harvard University Press.

Ploetzner, R., Lippitsch, S., Galmbacher, M., Heuer, D., \& Scherrer, S. (2009). Students' difficulties in learning from dynamic visualisations and how they may be overcome. Computers in Human Behavior, 25, 56-65.

Quintana, C., Reiser, B. J., Davis, E. A., Krajcik, J., Fretz, E., Duncan, R. G., et al. (2004). A scaffolding design framework for software to support science inquiry. The Journal of the Learning Sciences, 13, 337-387.

Reid, D. J., Zhang, J., \& Chen, Q. (2003). Supporting scientific discovery learning in a simulation environment. Journal of Computer Assisted Learning, 19, 9-20.

Sadeh, I., \& Zion, M. (in press). The development of dynamic inquiry performances within an open inquiry setting: A comparison to guided inquiry setting. Journal of Research in Science Teaching.

Scanlon, E., \& Smith, R. B. (1988). A rational reconstruction of a bubble-chamber simulation using the alternate reality kit. Computers \& Education, 12, 199-207.

Schwartz, D., \& Bransford, J. D. (1998). Time for telling. Cognition and Instruction, 16, 475-522.

Shimoda, T. A., White, B. Y., \& Frederiksen, J. (2002). Student goal orientation in learning inquiry skills with modifiable advisors. Science Education, 88, 244-263.

Shute, V. J., \& Glaser, R. (1990). A large-scale evaluation of an intelligent discovery world: Smithtown. Interactive Learning Environments, 1, 51-77.

Smith, R. B. (1986). The alternate reality kit: An animated environment for creating interactive simulations. Paper presented at the IEEE Computer Society workshop on visual languages.

Smith, R. B. (2010). The long history of gaming in military training. Simulation \& Gaming, 41, 6-19.

Swaak, J., \& de Jong, T. (2001). Discovery simulations and the assessment of intuitive knowledge. Journal of Computer Assisted Learning, 17, 284-294.

Swaak, J., de Jong, T., \& van Joolingen, W. R. (2004). The effects of discovery learning and expository instruction on the acquisition of definitional and intuitive knowledge. Journal of Computer Assisted Learning, 20, 225-234.

Tatar, D., Roschelle, J., Knudsen, J., Shechtman, N., Kaput, J., \& Hopkins, B. (2008). Scaling up innovative technology-based mathematics. Journal of the Learning Sciences, 17, 248-286.

Tobias, S., \& Duffy, T. M. (Eds.). (2009). Constructivist instruction. Success or failure? New York: Routledge. 
Tolentino, L., Birchfield, D., Megowan-Romanowicz, C., Johnson-Glenberg, M., Kelliher, A., \& Martinez, C. (2009). Teaching and learning in the mixed-reality science classroom. Journal of Science Education and Technology, 18, 501-517.

Toth, E. E., Suthers, D. D., \& Lesgold, A. M. (2002). "Mapping to know": The effects of representational guidance and reflective assessment on scientific inquiry. Science Education, 86, 264-286.

Towne, D. M., Munro, A., Pizzini, Q., Surmon, D., Coller, L., \& Wogulis, J. (1990). Model-building tools for simulation-based training. Interactive Learning Environments, 1, 33-50.

Trey, L., \& Khan, S. (2008). How science students can learn about unobservable phenomena using computerbased analogies. Computers \& Education, 51, 519-529.

Triona, L. M., \& Klahr, D. (2003). Point and click or grab and heft: Comparing the influence of physical and virtual instructional materials on elementary school students' ability to design experiments. Cognition and Instruction, 21, 149-173.

Tsui, C. Y., \& Treagust, D. F. (2003). Genetics reasoning with multiple external representations. Research in Science Education, 33, 111-135.

Urhahne, D., Nick, S., \& Schanze, S. (2009). The effect of three-dimensional simulations on the understanding of chemical structures and their properties. Research in Science Education, 39, 495-513.

van der Meij, J., \& de Jong, T. (2006). Supporting students' learning with multiple representations in a dynamic simulation-based learning environment. Learning and Instruction, 16, 199-212.

van Joolingen, W. R., \& de Jong, T. (1991). Supporting hypothesis generation by learners exploring an interactive computer simulation. Instructional Science, 20, 389-404.

van Joolingen, W. R., \& de Jong, T. (2003). Simquest: Authoring educational simulations. In T. Murray, S. Blessing, \& S. Ainsworth (Eds.), Authoring tools for advanced technology educational software: Toward cost-effective production of adaptive, interactive, and intelligent educational software (pp. 1-31). Dordrecht: Kluwer Academic Publishers.

van Merriënboer, J. J. G. (1997). Training complex cognitive skills: A four-component instructional design model for technical training. Englewood Cliffs, NJ: Educational Technology Publications.

Veermans, K. H., van Joolingen, W. R., \& de Jong, T. (2006). Using heuristics to facilitate scientific discovery learning in a simulation learning environment in a physics domain. International Journal of Science Education, $28,341-361$.

Wayne, D. B., Butter, J., Siddall, V. J., Fudala, M. J., Lindquist, L. A., Feinglass, J., et al. (2005). Simulation-based training of internal medicine residents in advanced cardiac life support protocols: A randomized trial. Teaching and Learning in Medicine, 17, 210-216.

White, B. Y., \& Frederiksen, J. (1998). Inquiry, modelling, and metacognition: Making science accessible to all students. Cognition and Instruction, 16, 63-118.

White, B. Y., \& Frederiksen, J. R. (1989). Causal models as intelligent learning environments for science and engineering education. Applied Artificial Intelligence, 3, 83-106.

White, B. Y., Frederiksen, J., Frederiksen, T., Eslinger, E., Loper, S., \& Collins, A. (2002). Inquiry island: Affordances of a multi-agent environment for scientific inquiry and reflective learning. Paper presented at the Fifth International Conference of the Learning Sciences (ICLS).

Wichmann, A., \& Leutner, D. (2009). Inquiry learning multilevel support with respect to inquiry, explanations and regulation during an inquiry cycle. Zeitschrift für pädagogische Psychologie, 23, 117-127.

Wieman, C. E., Perkins, K. K., \& Adams, W. K. (2008). Oersted medal lecture 2007: Interactive simulations for teaching physics: What works, what doesn't, and why. American Journal of Physics, 76, 393-399.

Wilhelm, P., \& Beishuizen, J. J. (2003). Content effects in self-directed inductive learning. Learning and Instruction, 13, 381-402.

Winberg, T., \& Hedman, L. (2008). Student attitudes toward learning, level of pre-knowledge and instruction type in a computer-simulation: Effects on flow experiences and perceived learning outcomes. Instructional Science, 36, 269-287.

Windschitl, M., \& Andre, T. (1998). Using computer simulations to enhance conceptual change: The roles of constructivist instruction and student epistemological beliefs. Journal of Research in Science Teaching, 35, $145-160$.

Winn, W., Stahr, F., Sarason, C., Fruland, R., Oppenheimer, P., \& Lee, Y.-L. (2006). Learning oceanography from a computer simulation compared with direct experience at sea. Journal of Research in Science Teaching, 43 , $25-42$.

Wu, H., Krajcik, J. S., \& Soloway, E. (2001). Promoting understanding of chemical representations: Students' use of a visualization tool in the classroom. Journal of Research in Science Teaching, 38, 821-842.

Zacharia, Z. C. (2007). Comparing and combining real and virtual experimentation: An effort to enhance students' conceptual understanding of electric circuits. Journal of Computer Assisted Learning, 23, 120-132. 


\section{6 - Research on Instruction}

Zacharia, Z. C., \& Anderson, O. R. (2003). The effects of an interactive computer-based simulation prior to performing a laboratory inquiry-based experiment on students' conceptual understanding of physics. American Journal of Physics, 71, 618-629.

Zacharia, Z. C., \& Constantinou, C. P. (2008). Comparing the influence of physical and virtual manipulatives in the context of the physics by inquiry curriculum: The case of undergraduate students' conceptual understanding of heat and temperature. American Journal of Physics, 76, 425-430.

Zacharia, Z. C., \& Olympiou, G. (in press). Physical versus virtual manipulative experimentation in physics learning. Learning \& Instruction.

Zacharia, Z. C., Olympiou, G., \& Papaevripidou, M. (2008). Effects of experimenting with physical and virtual manipulatives on students' conceptual understanding in heat and temperature. Journal of Research in Science Teaching, 45, 1021-1035.

Zhang, J., Chen, Q., Sun, Y., \& Reid, D. J. (2004). Triple scheme of learning support design for scientific discovery learning based on computer simulation: Experimental research. Journal of Computer Assisted Learning, 20, 269-282. 